\title{
Diagnóstico pelas técnicas histopatológicas e de Ziehl-Neelsen da tuberculose bovina de carcaça condenada em um frigorífico no Estado da Bahia
}

\author{
Diagnosis by techniques histopathology and Ziehl-Neelsen of bovine tuberculosis of \\ carcase condemned of a shambles the in state of Bahia
}

Leonardo Rosa da França ${ }^{1}$, Dante Sousa Lima², Filipe Ramon Bacelar de Carvalho², Mariana Sampaio Pinto $^{2}$, Paulo Natan Moreno Pereira Castro² ${ }^{2}$ Évelin Santiago Vasconcelos dos Santos ${ }^{3}$, Robson Bahia Cerqueira $^{4 *}$.

${ }^{1}$ Mestre em Defesa Agropecuária. UFRB; ${ }^{2}$ Acadêmico do Curso de Medicina Veterinária; ${ }^{3}$ Mestranda em Ciência Animal. UFRB; ${ }^{4}$ Doutor em Imunologia. UFBA. Mestre em Imunologia. UFBA. Professor Adjunto da UFRB.

\begin{abstract}
Resumo
Objetivo: descrever os achados sugestivos da presença do Mycobacterium bovis em bovinos abatidos num matadouro-frigorífico situado região sudoeste da Bahia, além de demonstrar a eficácia dos métodos tintoriais usados como presuntivos no diagnóstico da tuberculose bovina. Metodologia: no Laboratório de Patologia Veterinária (LPV) da Universidade Federal do Recôncavo Baiano (UFRB), foram analisadas 28 amostras de fragmentos de linfonodos bovinos fixados em formol a $10 \%$. Estas amostras foram processadas e coradas pelas técnicas de hematoxilina-eosina (H\&E) pela e a técnica de Ziehl-Neelsen (ZN). Resultados: o diagnóstico para tuberculose bovina foi feito após leitura das lâminas utilizando microscopia óptica. Das amostras histologicamente coradas por H\&E, em 78,6\% foi possível observar a presença de único ou múltiplos granulomas, sugestivos da doença. Destas amostras, 13,6\% demonstraram a presença de bacilos álcool ácidos resistentes (BAAR) após coloração com ZN. Conclusão: neste trabalho, evidenciou-se que a consorciação das técnicas histopatológicas H\&E e ZN torna o diagnóstico da tuberculose bovina mais eficiente do que quando as técnicas são processadas isoladamente.
\end{abstract}

Palavras-chave: Tuberculose. Granuloma. Hematoxilina. Eosina. Ziehl-Neelsen. Mycobacterium bovis.

\begin{abstract}
Objective: to describe the findings suggestive of the presence of Mycobacterium bovis in cattle slaughtered in a slaughterhouse fridge located southwest of Bahia, and demonstrate the effectiveness of dyeing methods used as presumptive diagnosis of bovine tuberculosis. Methodology: in Veterinary Pathology Laboratory (PVL) of Federal University of Recôncavo Baiano (UFRB), 28 samples of bovine lymphnodes fragments fixed in 10\% formalin were analyzed. These samples were processed and stained by hematoxylin and eosin technique (H\&E) and by Ziehl-Neelsen technique (ZN). Results: the diagnosis of bovine tuberculosis was made after reading the slides using optical microscopy. In the samples, histologically stained with H\&E, $78.6 \%$ were observed the presence of single or multiple granulomas suggestive of the disease. Of these samples, $13.6 \%$ showed the presence of bacilli acid-alcohol-fast, after staining with ZN. Conclusion: our results concluded that the combination of histopathological techniques is considerably more sensitive than these techniques processed separately.
\end{abstract}

Keywords: Tuberculosis. Granuloma. Hematoxylin. Eosin. Ziehl-Neelsen. Mycobacterium bovis.

\section{INTRODUÇÃO}

A tuberculose bovina (TB), zoonose de ocorrência mundial, causa grandes prejuízos econômicos à pecuária brasileira, por ser uma enfermidade que atua de maneira enzoótica nos rebanhos bovinos de corte ou leiteiros em todo território nacional, comprometendo a produtividade do plantel e consequentemente a produção nacional e exportações (CAMPOS, 2008; GLOBAL..., 2013). Os prejuízos econômicos estão relacionados principalmente à baixa produtividade, a óbitos no rebanho e a condenação de

Correspondente/ Corresponding: *Robson Bahia Cerqueira - Endereço: Rua Rui Barbosa, 710 - Campus Universitário CEP 44380-000, Cruz das Almas/BA CCAAB - Gabinete G-2. - Tel: (71) 9964-5118/(75)3621-7337 -E-mail: robsonba@gmail.com. carcaças em matadouros frigoríficos. Um animal tuberculoso pode apresentar 10 a $25 \%$ de queda na capacidade produtiva (BRASIL, 2006).

A TB, causada pelo Mycobacterium bovis, é uma doença infectocontagiosa de evolução crônica, cujo hospedeiro primário é o bovino, podendo acometer outras espécies como o homem por seu caráter zoonótico (HAAGSMA, 1995). M. bovis, contido na família Mycobacteriaceae, é um bacilo curto, aeróbico, imóvel, Gram-positivo, não esporulado, não possui cápsula e é álcool-ácido resistente. A TB Caracteriza-se pela formação de granulomas nodulares específicos denominados de tubérculos, que podem estar localizados em qualquer órgão ou tecido (CORREIA; CORREIA, 1992; RUGGIERO, 2004). 
A manifestação da doença no hospedeiro depende de fatores diversos valendo destacar, resposta imune, via de infecção e virulência do microrganismo que determinam ainda a sobrevivência e multiplicação do mesmo no animal (AYELE et al., 2004). A inalação de aerossóis contaminados com o microrganismo é responsável por aproximadamente $90 \%$ das infecções em bovinos e bubalinos (EL KIK JÚNIOR; SOUZA, 2008; MARQUES; MAIA JUNIOR; ZAPPA, 2008; PACHECO et al. 2009; LAVAGNOLI et al., 2010; PÉREZ-LAGO; NAVARRO; GARCÍA-DE-VIEDMA, 2014).

No cenário da inspeção sanitária durante o exame post mortem, usualmente, as amostras suspeitas encontradas são adequadamente coletadas e rapidamente encaminhadas para exames bacteriológicos e histopatológicos com o objetivo de comprovação e controle do diagnóstico realizado a campo e para a avaliação da eficácia das provas de tuberculina (ORGANIZACIÓN PANAMERICANA DE LA SALUD, 1995).

Em 95\% dos casos, as lesões estão localizadas em linfonodos (mediastínicos, retrofaríngeos, bronquiais, parotídeos, cervicais, inguinais superficiais e mesentéricos), pulmão e fígado. Com menor frequência, podem estar presentes em intestino e tecido mamário, ou em qualquer outro órgão ou tecido do animal (BRASIL, 2006). Portanto para um diagnóstico eficaz da infecção faz-se necessário junto ao método de isolamento do microrganismo, uso de técnicas complementares (FRÁGUAS et al., 2008; FURLANETTO et al., 2012)

O Ministério da Agricultura, Pecuária e Abastecimento (2006) recomenda que as amostras frescas de tecidos suspeitos podem ser fixadas em lâmina e coradas pelo método de ZN para a pesquisa de BAAR. O MAPA preconiza o envio de parte do material para exames histopatológicos, a fim de pesquisar tecido de granulação. $O$ diagnóstico definitivo da TB bovina é realizado mediante o isolamento e a identificação do agente por métodos bacteriológicos.

O presente estudo foi realizado com o objetivo de descrever achados sugestivos da TB bovina em amostras de tecidos de animais abatidos em um matadouro-frigorífico da região sudoeste da Bahia, avaliando resultados das técnicas de H\&E e ZN a fim de auxiliar na rotina do diagnóstico da doença.

\section{METODOLOGIA}

Vinte e oito amostras de fragmentos de linfonodos, selecionados durante a inspeção de bovinos abatidos num frigorífico da região sudoeste da Bahia provindos de cidades diversas, foram coletadas no período de março a julho do ano de 2012. Estes animais tinham entre 2 e 5 anos de idade sendo 22 fêmeas e 6 machos.

\section{AMOSTRAS}

Os linfonodos que apresentaram lesões nodulares, de tamanhos e formas variadas, contendo exsudato purulento, caseoso ou calcificado foram considerados sugestivos para TB bovina, seguindo a recomendação de Wangoo et al. (2005) que descreve as lesões como área central com necrose caseosa por vezes com focos de mineralização, circundado por intenso infiltrado inflamatório composto por neutrófilos, linfócitos, macrófagos, células epitelióides de células gigantes e áreas delimitadas por tecido fibroso. Em algumas secções as lesões foram delimitadas por tecido fibroso. Desses linfonodos foram retirados fragmentos com tamanho aproximado de $2 \mathrm{~cm}^{2}$. As amostras, com cerca de $1 \mathrm{~cm}^{2}$, foram fixadas em formol a $10 \%$, armazenadas em frascos tipo coletor universal e encaminhados ao LPV da UFRB.

\section{TÉCNICAS ZN e H\&E}

Fragmentos na zona de transição entre a área lesada e a área aparentemente normal foram retirados e colocados em um cassete para a inclusão em parafina. Num micrótomo, foram cortadas fitas a $5 \mu \mathrm{m}$, depois pescadas por lâminas onde foram montadas, obtendo duas lâminas de cada amostra. Antes do processo de coloração dessas lâminas, estas passaram por uma técnica de preparação para desparafinizar, hidratar e montar o corte usando uma sequência a base de Xilol, Álcool 95\%, e por último, lavagem em água destilada.

Dois processos de coloração foram realizados após confecção das lâminas. A técnica de H\&E, para coloração do tecido com granuloma e a técnica de ZN para identificação do BAAR. Os achados histopatológicos foram interpretados como sugestivo ou negativo para micobactéria com base nas classificações descritas por Ohara (2006) e Varello et al. (2008). A leitura foi realizada em microscópio óptico Olympus ${ }^{\circledR}$, Modelo CX21FS1.

\section{RESULTADOS}

Dentre as amostras examinadas coradas por H\&E, em $22(78,6 \%)$ delas foi possível observar presença de único ou múltiplos granulomas (Figura 1). Na coloração pela técnica de $Z N$, $3(13,6 \%)$ foi detectada a presença de BAAR (Figura 2).

Figura 1 - Lâmina corada com H\&E demonstrando tecido com presença de cápsula de granuloma

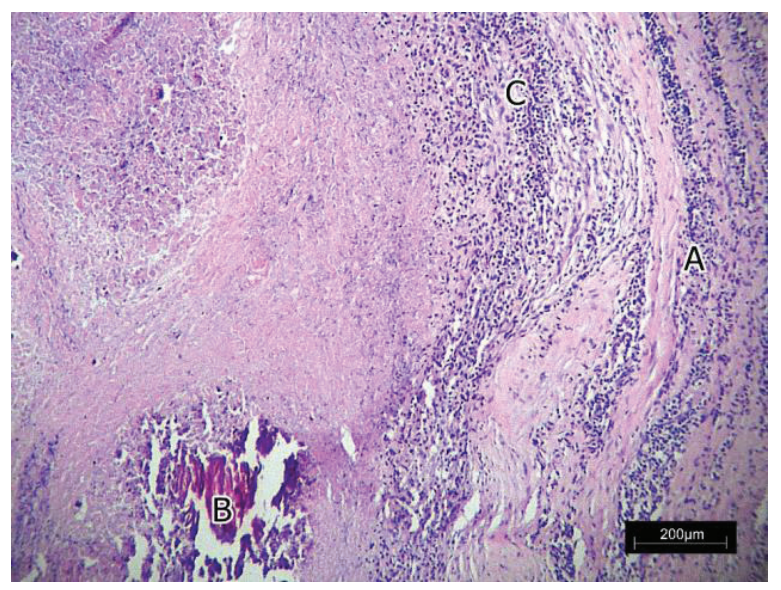

Legenda: (A): processo necrótico com mineralização (B): infiltrado de células linfóides com núcleo enegrecido (C): Obj. 10X. 
Figura 2 - Lâmina com técnica de Ziehl-Neelsen identificando BAAR (corado em vermelho), Obj. 40X.

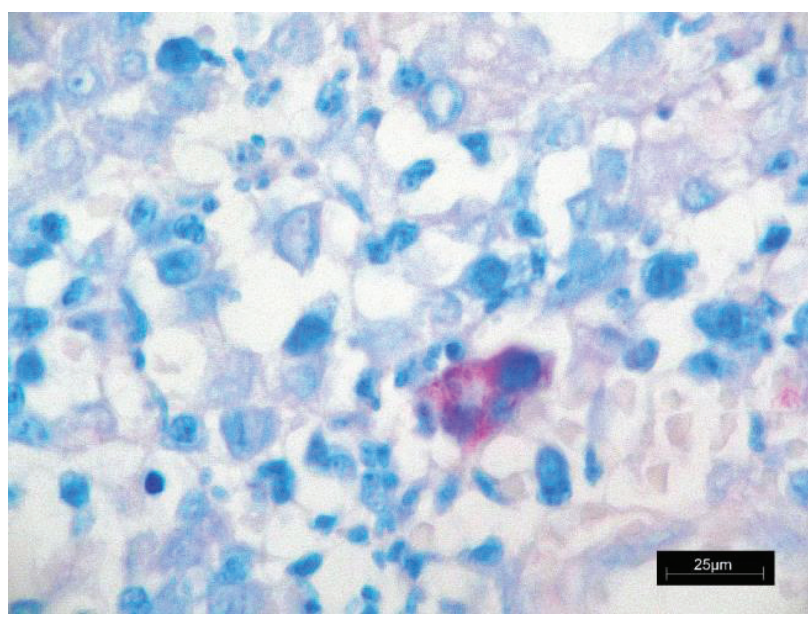

\section{DISCUSSÃO}

As lesões provocadas pelo $M$. bovis não são patognomônicas da TB bovina, apresentando coloração amarelada em bovinos. São nódulos de $1 \mathrm{a} 3 \mathrm{~cm}$ de diâmetro ou mais, que podem ser confluentes, de aspecto purulento ou caseoso, com presença de cápsula fibrosa, podendo apresentar necrose de caseificação no centro da lesão, ou, ainda, calcificação nos casos mais avançados (BRASIL, 2006).

Em estudo realizado por Fráguas et al. (2008), no Rio de Janeiro, foi encontrado resultado semelhante com $64,95 \%$ de animais apresentando lesão granulomatosa característica quando corados pela H\&E, sendo todas estas associadas à presença de lesões macroscópicas, porém os resultados encontrados por Pinto et al. (2002) foram bastante inferiores totalizando $18 \%$.

De acordo com o Ministério da Agricultura, Pecuária e Abastecimento, amostras frescas podem ser fixadas em lâmina e coradas pelo método de ZN para a pesquisa de BAAR. A sensibilidade do método é baixa, e um resultado positivo sugere fortemente tratar-se de micobactéria, mas não informa a espécie. Muitas características, inclusive a propriedade tintorial, superpõem-se os gêneros Mycobacterium e Nocardia, tornando difícil, em alguns casos, a diferenciação de ambos.

Barksdale e Kim (1977) afirmaram que a técnica do ZN é um método de diagnóstico direto rápido e barato, porém só consegue revelar a presença de BAAR em concentrações superiores a $10^{4}$ bactérias $/ \mathrm{mL}$. Uma possível explicação para a baixa frequência de BAAR em relação ao número de lesões sugestivas ao exame histopatológico pode ser devido a baixa taxa de sobrevivência das micobactérias, perda de estrutura bacteriana em razão das respostas imunitárias (ANDRADE et al., 1991) ou baixa concentração de bacilos na lesão examinada (PALMER; WATERS, 2006).

Os métodos diretos de diagnóstico, com base na visualização ou isolamento do agente etiológico a partir de lesões oriundas de animais doentes, são sem dúvida os mais confiáveis e inequívocos, sendo considerados como "padrão-ouro" de diagnóstico (LILENBAUM, 2000).

\section{CONCLUSÃO}

Evidenciou-se que a consorciação das técnicas estudadas torna o diagnóstico mais seguro. A técnica $\mathrm{H} \& E$ indica a presença de granulomas e o método de ZN evidencia a presença de BAAR, sendo ambos presuntivos e complementares no diagnóstico da TB bovina.

\section{REFERÊNCIAS}

1. ANDRADE, G. B. et al. Estudo histológico e isolamento de micobactérias de lesões similares à tuberculose em bovinos no Rio Grande do Sul. Pesqui. vet. bras., Rio de Janeiro, v.11, n.3/4, p. 81-86, dez.1991.

2. AYELE, W. Y. et al. Bovine tuberculosis: an old disease but a new threat to Africa. Int. j. tuberc. lung dis., Paris, v. 8, n. 8, p. 924-937, Aug.2004.

3. BARKSDALE, L.; KIM, K. S. Mycobacterium. Bacteriol. Rev., New York, v. 41, n. 1, p. 217-372, Mar.1977.

4. BRASIL. Ministério da Agricultura, Pecuária e Abastecimento(MAPA). Departamento de Saúde Animal. Programa Nacional de Controle e Erradicação da Brucelose e Tuberculose (PNCEBT): Manual Técnico. Brasília: MAPA, 2006. 188p.

5. CAMPOS, S. S. Prevalência de tuberculose bovina. Saber Digital: Rev. Elet. CESVA, Valença, Bahia, v. 1, n. 1, p. 245, mar./ ago.2008.

6. CORREIA, M.; CORREIA, N. M. Enfermidades Infecciosas dos Mamíferos Domésticos. Belo Horizonte-MG: MEDSI, 1992. p.317-337.

7. EL KIK JÚNIOR, M.; SOUZA, C. L. M. de. Considerações sobre a tuberculose bovina no norte Fluminense e no município de Campos dos Goytacazes após o advento do PNCEBT - Programa Nacional de Controle e Erradicação da Brucelose e Tuberculose Bovina. Persp. online, Campos dos Goytacazes (RJ), v. 2, n. 8, p. 138-148, 2008.

8. FRÁGUAS, S. de A. et al. Estudo comparativo de métodos complementares para o diagnóstico da tuberculose bovina em animais reagentes à tuberculinização. Rev.bras. ciênc. vet., Niterói, v. 15, n. 3, p. 117-121, 2008.

9. FURLANETTO, L. V. et al. Uso de métodos complementares na inspeção post mortem de carcaças com suspeita de tuberculose bovina. Pesqui. vet. bras., Rio de Janeiro, v. 32, n. 11, Nov.2012.

10. GLOBAL tuberculosis Report 2013. Geneva: World Heatlh Organization (WHO), 2013. $304 \mathrm{p}$.

11. HAAGSMA, J. Bovine tuberculosis. Geneve: Office international des Épizooties, 1995. 11p. (Manual Amendment, 2).

12. LAVAGNOLI, M. R. et al. Tuberculose em bovinos no Estado do Espírito Santo. Vet. zoot., São Paulo, v. 17, n. 1, p. 71-78, 2010.

13. LILENBAUM, W. Atualização em Tuberculose Bovina. uma mini revisão. Rev. bras. med. vet., Rio de Janeiro, v. 22, n. 4, p.145-151, 2000.

14. MARQUES, M. E. de O.; MAIA JUNIOR, J. F.; ZAPPA, V. Controle da Tuberculose Bovina. Rev. Cient. Elet. Med. Vet., São Paulo, v. 6, n. 10, p.1-5, jan. 2008.

15. ORGANIZACIÓN PANAMERICANA DE LA SALUD. Situación de la tuberculosis bovina en las Américas. Espanha: OPS/OMS, Abr.1995. 6 p.

16. OHARA, P. M. Microbiologia e histopatologia de linfonodos com lesões macroscópicas sugestivas de tuberculose. 2006. $106 \mathrm{f}$. Dissertação (Mestrado) - Faculdade de Medicina Veterinária e Zootecnia, Universidade de São Paulo, São Paulo, 2006. 
17. PACHECO, A. M. et al. Tuberculose bovina - relato de caso. Rev. Cient. Elet. Med. Vet., São Paulo, v. 7, n. 13, p.1-5, jul. 2009.

18. PALMER, M. V.; WATERS, W. R. Advances in bovine tuberculosis diagnosis and pathogenesis: what policy makers need to know. Vet. microbiol., Amsterdam, v. 112, n.2/4, p. 181-190, Feb.2006.

19. PÉREZ-LAgO, L.; NAVARRO, Y.; GARCíA-DE-VIEDMA, D. Current knowledge and pending challenges in zoonosis caused by Mycobacterium bovis: A review. Res. Vet. Sci., London, v. 97, n.1, p.94-100, Oct. 2014.

20. PINTO, P. S. A. et al. Exame microbiológico da Tuberculose como subsídio à inspeção post-mortem de bovinos. Rev. Bras. Saúde Prod. An., v. 3, n. 1, p. 10-15, 2002.
21. RUGGIERO, A. P. M. Métodos moleculares aplicados ao diagnóstico da tuberculose bovina. 2004. Dissertação (Mestrado em Epidemiologia Experimental e Aplicada às Zoonoses) - Faculdade de Medicina Veterinária e Zootecnia, Universidade de São Paulo, São Paulo, 2004. Disponível em: <http://www.teses.usp.br/teses/disponiveis/10/10134/ tde-18012005-154235/>. Acesso em: 10 fev. 2013.

22. VARELLO, K. et al. Comparison of histologic techniques for the diagnosis of bovine tuberculosis in the framework of eradication programs. J. vet. diagn. invest., v. 20, n.2, p. 164-169, Mar.2008.

23. WANGOO, A. et al. Advanced granulomatous lesions in Mycobacterium bovis-infected cattle are associated with increased expression of type I procollagen (WC1+) T cells and CD 68+ cells. J. comp. pathol., v. 133, n. 4 , p. 223-234, 2005.

Submetido em: 02/09/2014

Aceito em: 19/09/2015 